\title{
ICT BANKING STRATEGIES DESIGNED TO GROW AND RETAIN E-COMMERCE: ALTERNATE DELIVERY CHANNELS' CUSTOMER BASE
}

\author{
Rudolph Strong, University of Wisconsin Stout, strongr6116@my.uwstout.edu
}

\begin{abstract}
The following is a summary of potential Information Communication Technology (ICT) strategies that can be employed to position banks to be successful in developing alternate delivery channels. The goal of this document is to highlight what ICT Technologies and high-level processes, objectives, and tasks managers can accomplish that would contribute to the success of their alternate delivery channels' goals.
\end{abstract}

Keywords: Information Communication Technology (ICT), Alternate Delivery Channel (ADC), Bank, Mobile, Social media

\section{INTRODUCTION}

Bowman, van den Hoff, van den Wijngaert, \& van Dijk (2005) states that the convergence of telecommunications and computer technology is generally defined as information communication technology (ICT). The financial industry is increasingly employing ICT in the form of alternate delivery channels (ADCs). Within the banking industry, ADCs are methods other than traditional bank branches that banks use to meet their customers' needs. Banker, Chen, Liu, and Ou (2009) found that adopting ADCs enables banks to retain and expand their market share (Hannan \& McDowell, 1990; Kauffman \& Kumar, 2008). Today's modern financial institutions will need to use Information Communication Technology (ICT) banking strategies to grow and retain each e-commerce alternate delivery channel's customer base as well as increasing the overall bank customer base through the effective/efficient utilization of available channels.

Bank executives looking to attract new customers while engaging and reducing the attrition of existing customers can use alternate delivery channels as an end to their means. In this paper, I aim to explore current ICT advances in mature channel technologies and potential opportunities in emerging technologies, such as mobile banking and social media, as an alternate delivery channel. The research approach will be to investigate and discover the range of answers to our research questions and then present findings, solutions, and conclusions to readers. The ATMs were one of the first ICT technologies to be used by banks, and it has remained one of the most successful. The ATM is a computerized telecommunications device that provides bank customers with self-service access to their financial accounts. A prototype was first created in 1939, a modern ATM was patented in 1966, an ATM was installed in a Barclays Bank in London in 1967, and the United States started producing ATMs in 1968 (Bellis, n.d.).

Alternate delivery channels such as ATMs, Telephone Interactive Voice Response (IVR) systems, and online banking are mature channels, but advances in ICT permit opportunities for enhancements even in these established technologies. The proven success of ICT in ATMs, online banking, and IVRs clearly demonstrates the revenue impact of these technologies. Current popular alternate delivery channel technologies include service such as the following: short message service (SMS) banking text alerts, bill pay, automated clearing house (ACH) electronic payments, mobile banking, e-mail alerts and notifications, fax banking services, video banking, and online social media banking. These technologies are all relatively recent ICT enabled ADC strategies that banks can employ (Koltveit, J., and Owens J. P., 2000). Mobile banking is one of the newer technologies being considered and is increasingly being adopted. Social media is beginning to draw attention, but security concerns still remain that have prevented wide-scale adoption of either technology in the financial industry.

Fax banking services are also being offered by some banks that provide a dedicated hotline for receiving customers' written instructions. With this service, you always have the option of faxing your instructions and requests for banks to act upon them immediately. Fax banking can include payment and transfer instructions, 


\section{Issues in Information Systems}

\section{Volume XII, No. 1, pp. 1-6, 2011}

standing instructions to be included or excluded from particular services, requests for account statements, special instructions, and requests for bank certification of documents. New channels like video banking are in their infancy and are typically thought of as the logical path to ATM enhancements or replacement. In video banking, banking consultations or transactions take place via a remote video connection. Video banking uses the latest ICTs but it can be a costly ADC to implement.

Even though ADC can be costly and time intensive to implement Banker et al. (2009) note that customers may decide where to bank based on the availability of ADCs, which therefore impact a bank's profitability. The American Bankers Association found that, in 2007, 36\% of surveyed bank customers preferred to bank at a branch office; however, by 2009 that percentage had dropped to $21 \%$, with $25 \%$ of surveyed customers preferring to bank online (as cited in Kaplan, 2009; see Figure 1).

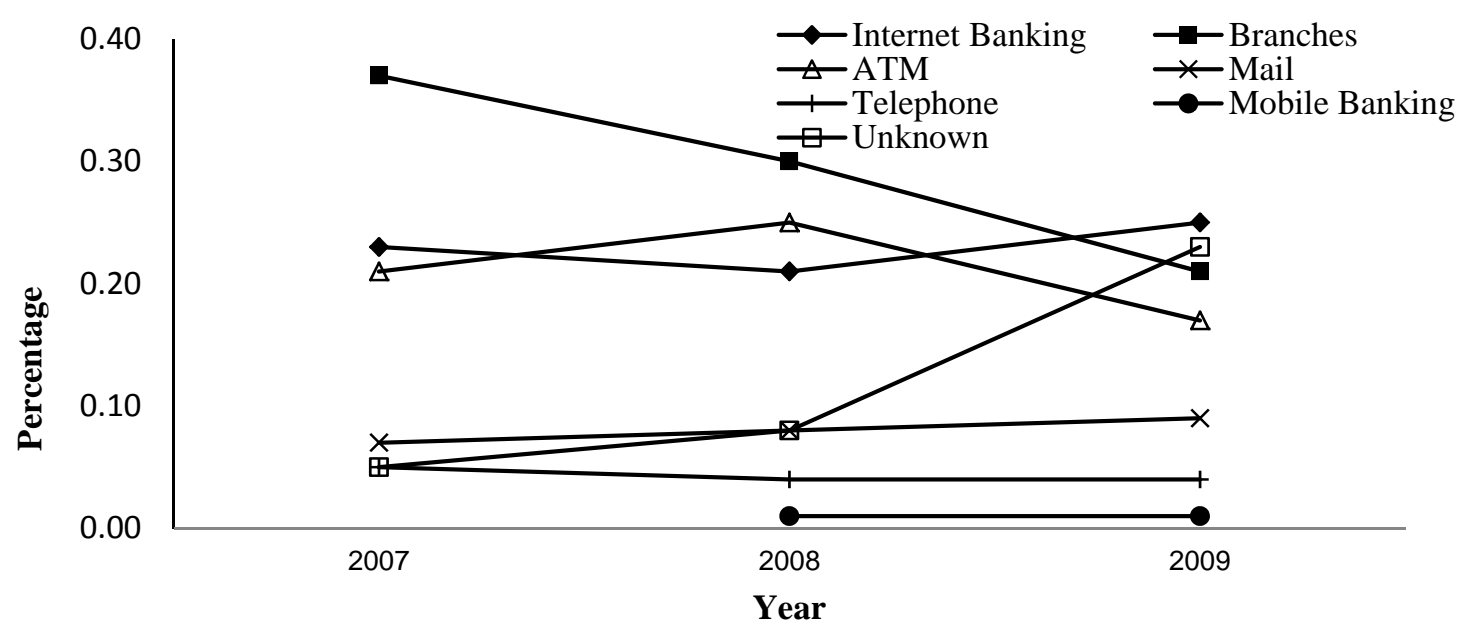

Figure 1. Preferred banking method, all age groups.

From “ABA Survey: Consumers Prefer Online Banking,” by C. Kaplan. Copyright 2009 by the American Bankers Association.

ADCs can be direct or indirect (Saxena, 2009). Direct channels are owned or largely controlled by the bank (Saxena, 2009). They can be location-based (e.g., branch offices or other departments or business units) or remote (e.g., online, call centers, or IVRs). Indirect channels include ATMs or credit-card services that are provided to a bank by another firm. When banks partner with other firms to deploy ATMs and provide credit card services, this is an example of indirect channels. Table 1 presents the main features of the different types of ADCs

From “Accelerating Financial Inclusion Through Innovative Channels: 10 Obstacles for MFIs Launching Alternative Channels—and What Can Be Done About Them,” by A. Saxena, 2009, InSight, 27. Copyright 2009 by ACCION International.

Most ICT advancements in banking have generally been direct location based channels focused on the individual customer. Banks have used indirect alternate delivery channels to allow customers 24/7, anytime, anywhere, access to their account information and the ability to make secure and easy financial transactions. 


\section{Issues in Information Systems}

Volume XII, No. 1, pp. 1-6, 2011

Table 1

Types of Alternative Channels and Main Features

\begin{tabular}{|c|c|c|c|c|c|c|}
\hline inel Type & Features & $\begin{array}{l}\text { ational/Real } \\
\text { e Intensity }\end{array}$ & $\begin{array}{l}\text { nological } \\
\text { Isity }\end{array}$ & $\begin{array}{l}\text { latory } \\
\text { ness }\end{array}$ & $\begin{array}{l}\text { 1-Party } \\
\text { agement } \dagger\end{array}$ & $\begin{array}{l}\text { - }- \text { Term } \\
\text { ementation } \dagger\end{array}$ \\
\hline ¿CT Location & $\begin{array}{l}\text { l-estate heavy } \\
\text { e-to-face } \\
\text { mer } \\
\text { iction }\end{array}$ & & & & (typically) & (3-6 months) \\
\hline $\begin{array}{l}\text { ICT } \\
\text { ote }\end{array}$ & $\begin{array}{l}\text { Inol-ogy- } \\
1 \\
\text { h Investment }\end{array}$ & & um-High & Medium & $\begin{array}{l}\text { Medium } \\
\text { lly technical } \\
\text { lltants) }\end{array}$ & $\begin{array}{l}\text { um (6-12 } \\
\text { hs) }\end{array}$ \\
\hline RECT & $\begin{array}{l}\text { d-Party } \\
\text { gement• } \\
\text { latory } \\
\text { guity }\end{array}$ & um & hronizat-ion) & $\begin{array}{l}\text { (vague, } \\
\text { sing) }\end{array}$ & $\begin{array}{l}\text { (agents, } \\
\text { iers, } \\
\text { ces) }\end{array}$ & (6-24 months) \\
\hline
\end{tabular}

Notes: † Includes consulting firms, agents, suppliers, and strategic alliances.

\section{TECHNOLOGY}

One possible solution to increasing the overall bank customer base is to utilize ICT advances in indirect delivery channels such as mobile banking and social media to attract and retain new, younger, customers. Kitten (2010) found that mobile technology is already having a big impact on financial services, from remote banking to mobile payments, and states that continued proliferation of smart phones is only going to accelerate that impact. Mobile is already revolutionizing the way consumers interact with their financial institutions, and banks have to stay ahead of the technology and security concerns. Butcher (2010) reported in a mobile technology trade publication that a payments executive at the Mobile Shopping Summit said that mobile commerce is expected to grow from $\$ 2.4$ billion this year to $\$ 23.4$ billion by 2015, an 875 percent increase. Mobile banking ICT technologies allow banks to offer services such as text (SMS) banking, mobile applications for iPhone, Blackberry, and Droid phones, .mobi site websites designed to be viewed on mobile phones, mobile deposit capture 'point-click-deposit' technology that accept checks from a customer's mobile phones, and mobile payments where, instead of paying with cash, check, or credit cards, a consumer can use a mobile phone to pay. Business merchants are also starting to implement mobile banking solutions as part of their business account transactions. $4 \%$ of Businesses use mobile banking today , but 65\% would like to use it (Crosman, 2010).

ADCs can present competitive advantages such as lower cost per transaction, reduced time to respond to customers, and the generating of leads to cross sale products. Telephone IVR systems can perform transfers at lower cost than bank branches. In his book Bank 2.0, King (2010) describes mobile banking as "by far the lowestcost bank channel on a per-transaction basis, averaging about 8 cents per transaction versus $\$ 4$ for the branch and $\$ 3.75$ for the call center” (p. 221). Currently there are four models for mobile payments: premium SMS-based transactional payments, direct mobile billing, mobile web payments WAP (Wireless Access Protocol), and contactless NFC (Near Field Communication), where a consumer using a special mobile phone equipped with a smartcard waves his/her phone near a reader module. Verizon (2010), a major telecom company, predicts that, in the next ten years, mobile, online, and telephone banking channels will become channels of choice for personal banking, while branch network use will significantly shift towards advisory services. In a recent Pew Research study it was found that $40 \%$ of adults use the Internet, e-mail, or instant messaging features on a mobile phone (Pew, 2010). 


\title{
Issues in Information Systems
}

\author{
Volume XII, No. 1, pp. 1-6, 2011
}

Visible-Banking.com (2010) reported that, in March 2009, Visible Banking founder Christophe Langlois started tracking the financial institutions (FIs) on Facebook and Twitter and, at that time, only 54 accounts existed. Today Visible Banking Facebook Watch Series is now tracking 617 pages, groups, and applications in 67 countries: 372 from banks, 100 from credit unions, 86 from insurance firms, 30 from financial services and investment firms, and 29 from credit card companies. Their Twitter Watch Series is now tracking 1,333 accounts in 68 countries: 669 from banks, 338 from credit unions, 217 from insurance firms, 69 from financial services and investment firms, and 40 from credit card companies. One could conclude that these new technologies offer potential for future channel successes based on the past performance ICT has had on the adoption of alternate delivery channels. For bank executives the challenge of determining which ICT channel technologies will be best suited for their customers and organization and yield a good return on investment (ROI) is a significant challenge in our current weak economy. Possible obstacles to achieving a good ROI when implementing ICT based ADCs include high costs of capital, production, and marketing; a need to win consumer acceptance and achieve brand recognition; and the need to train staff with respect to the new technology. Branch managers, customer-service agents, and other bank staff play important roles in the successful implementation of new technologies.

To assess the ROI of a new ICT such as mobile banking or social media as an ADC implementation, managers can consider such key performance indicators as ADC impact to overall bank net income, revenue per channel, customer satisfaction per channel, overall growth of the customer base, overall reduction in customer attrition, percent of time of channel availability for customer use, customers utilization percentages per channel, and percentage of accounts signed up for ADCs.

Bank managers' strategies for marketing ADCs can include working with the marketing department to gather data, develop a marketing plan, and project sales. They can also include analyzing already-existing data available in trade publications, from online sources, and from trade associations.

An important implementation consideration to also note is that ADCs that work well for large banks may not work well for small or midsize banks. In deciding which ADCs to implement, bank managers much consider the total size of the market, their projected share of the market, current demand in their target market, trends within the target market, and trends in consumer preferences. Bank managers need extensive information on the demographic characteristics of their targeted customers, such as their age, gender, location, income level, social class, occupation, and level of education.

\section{IMPACT ANALYSIS}

Bank managers must also consider the impact of product trends, trends within the industry, their bank's potential for growth, and competing products and companies. For instance, how do changes in technology, the economy, and government regulations affect the bank's overall goals and their ICT enabled ADC implementation? There can be social impacts to an ICT implementation. Social-media ADCs can appeal to customers who frequently participate in online social networking. According to the Schmitz and Fulk social influence model, "the use of ICT is determined by personal preferences... Individual users' social environment is an important influence in their media choice and use” (Bowman et al., 2005, p. 99).

Providing SMS alerts when balances or purchases reach a certain amount can have a psychological impact by helping customers feel more confident about managing their finances and better protected against identify theft. Environmental impacts can also be found as some ADCs also help protect the environment. Online banking and electronic statements have less environmental impact than use of traditional brick-and-mortar bank branches.

In implementing ADCs the political impact of an ICT channel must also be addressed. Bank managers must be careful that their ADCs are in compliance with all regulations and laws, some of which are unique to e-banking and some of which apply to traditional banking but must also be adhered to in an ICT implementation. For example, Regulation B of the Equal Credit Opportunity Act and Regulation C of the Home Mortgage Disclosure Act require banks to collect and report certain information on loan applications. Regulation B of the Equal Credit 


\title{
Issues in Information Systems
}

\author{
Volume XII, No. 1, pp. 1-6, 2011
}

Opportunity Act and regulations associated with the Fair Credit Reporting Act also specify certain requirements with regard to record retention.

However, ADCs also have disadvantages. Low-income customers can be slow to adopt new technologies. Also, it can be challenging to identify the dollar ROI of new ICT and to determine pricing and fees for products and services.

Security risks may be the primary reason that many financial institutions and consumers have been slow to adopt mobile banking and social-media technologies. Banks and consumers have concerns about the possible consequences when customers lose their mobile phones or someone hacks into a bank's social-media account. To address such concerns, Facebook recently implemented new security measures (Sutter, 2010). Users can specify particular computers and mobile phones that should have access to their Facebook accounts. To access an account from a new computer or, say, a friend's phone, the user may have to answer a security question. If someone tries to $\log$ in to a Facebook account from an unauthorized device, Facebook notifies the account holder by e-mail or text message, presumably allowing the account holder to shut down before any personal information is stolen. According to mobile-security consultant Jason Rouse, NFC is inherently less secure than traditional banking methods (as cited in Kitten, 2010). However, in his opinion, banks and credit unions should not rule out offering mobile payments as long as they adequately prepare for security risks such as potential interception of transactions (as cited in Kitten, 2010). The banking industry is increasingly using Web and mobile applications that address security concerns raised by e-banking.

\section{RECOMMENDATION}

It will become increasingly more challenging for banks to grow and retain their customer base without implementing new ICT alternate delivery channel technologies or, at minimum, enhancing current technologies. The historical success of such ICT enabled ADCs as ATMs, online banking, and telephone IVR systems has shown that ICT plays an important role in the banking industry. ICT advances such as ATM check imaging, voice recognition, and video banking provide opportunities to enhance these mature technologies.

New technologies in mobile banking, social media will be the next wave of ICT for banks to focus on. Alternate delivery channels are the infrastructures best suited for ICT Implementations. With the mass growth and adoption of mobile phone and social media technologies, banks should focus on ways to capitalize on this movement and see what current alternate delivery channel business process would provide the best long-term ROI.

The banking industry currently is beginning to rapidly adopting mobile banking and starting to employ online social media. Tubin (2010) found that Mobile banking adoption has exceeded initial expectations by over 100 percent for all banks surveyed, with many witnessing over 10 percent of their online banking customers taking up the mobile channel within the first year.

The Raddon Financial Group (RFG)'s national consumer research found that 54 percent of all consumers in the United States are on some type of social networking site. Forty-six percent of the country is on Facebook alone, with 88 percent of users logging on at least once a month. Thirty-five percent of the population uses Facebook daily or weekly (Rothaar, 2010).

Langlois (2009) states that there is not one type of ROI from social media and that social media should not be seen as a sales channel but it will still help increase brand familiarity, the inclination to buy, reduce customer service costs, drive online banking usage, or employee recruitment. This research clearly suggest that to maintain and expand their customer base, today's financial institutions need to use ICT in ADCs effectively and efficiently. King (2010) states:

A staggering 90 per cent of daily transactions are executed electronically today. Institutions that hold on to the belief that physical branches remain at the core of what the brand does, will not adapt easily to the customer of 


\title{
Issues in Information Systems
}

\author{
Volume XII, No. 1, pp. 1-6, 2011
}

tomorrow who rarely visits a branch or the customer who sees no need for an over-the-counter transaction with cash or checks. Those who still classify the Internet, ATM and iPhone applications as "alternative" channels will be playing catch up for the next decade, while intermediaries will increasingly capture niche service opportunities. (p. preface)

\section{REFERENCES}

1. Banker, R., Chen, P., Liu, F., Ou, C. (2009). Interdependence of alternative service channels on bank performance. Track: Extended Abstract for Research-in-Progress. Retrieved October 14, 2010,from http://pages.stern.nyu.edu/ bakos/wise/papers/wise2009-p12_paper.pdf

2. Bellis, M. (n.d.). The ATM machine of Luther Simjian. Retrieved October 14, 2010, from http://inventors.about.com/od/astartinventions/a/atm.htm.

3. Bowman, H., van den Hoff, B., van den Wijngaert, L., \& van Dijk, J. (2005). Information and communication technology in organizations. London: Sage Publications.

4. Butcher, D. (2010). Mobile commerce to grow 875pc over next 5 years: Amazon exec. Mobile Commerce Daily. Retrieved on October 27, 2010, from http://www.mobilecommercedaily.com/mobile-commerce-to-grow-875pcover-next-5-years-amazon-exec/.

5. Crosman, P. (2010). 4\% of Businesses Use Mobile Banking, But 65\% Would Like to Use It, Aite Survey Finds. Bank Systems Technology. Retrieved November 10, 2010, from http://banktech.com/channels/228200507

6. Hannan, T. H., and McDowell, J. M. (1984). The determinants of technology adoption: The case of the banking firm. The RAND Journal of Economics, pp. 328-335.

7. Kaplan, C. (2009). ABA survey: Consumers prefer online banking. American Bankers Association Survey. Retrieved October 25, 2010, from http://www.aba.com/Press+Room/092109ConsumerSurveyPBM.htm.

8. Kauffman, R.J., and Kumar, A. (2008). Understanding state and national growth co-movement: A study of shared ATM networks in the United States. Electronic Commerce Research and Applications (7:1), pp 21-43.

9. King, Brett. (2010). BANK 2.0: What's the future of your bank. Singapore: Marshall Cavendish International.

10. Kitten, T. (2010). The future of mobile payments. Bank Info Security. Retrieved October 27, 2010, from http://www.bankinfosecurity.com/articles.php?art_id=3017.

11. Koltveit, J., and Owens J. P. (2000). Ten Challenges Facing Community Banks. Commercial Lending Review. Retrieved October 27, 2010, from http://mcgladreypullen.com/Resource_Center/Articles/FI/Ten_Challenges.pdf

12. Langlois, C. (2009). Not embracing social media presents a new risk. Trend 219, $28-29$.

13. Pew Research Center. (2010, July 7). Mobile Access 2010. Retrieved October 28, 2010, from http://pewinternet.org/Reports/2010/Mobile-Access-2010.aspx.

14. Rothaar, M. (2010). Social media for financial institutions: sliced bread or burnt toast. The Raddon Report. Retrieved October 28, 2010, from http://www.theraddonreport.com/?p=3037.

15. Saxena, A. (2009). Accelerating financial inclusion through innovative channels: 10 obstacles for MFIS launching alternative channels - and what can be done about them. Insight. Retrieved October 16, 2010, from http://resources.centerforfinancialinclusion.org/insight/?L=E.

16. Sutter, J. D. (2010). Facebook launches new security feature. CNNTech. Retrieved October 27, 2010, from http://articles.cnn.com/2010-05-14/tech/facebook.security.privacy_1_facebook-users-users-more-controlprivacy?_s=PM:TECH

17. Tubin, G. (2010). Lessons Learned: Eight US Financial Institutions Reveal Mobile Banking Benefits. TowerGroup. Retrieved November 10, 2010, from http://www.clairmail.com/towerstudy

18. Verizon Business. (2010). Top Trends in Financial Services. Retrieved October 28, 2010, from http://www.verizonbusiness.com/resources/factsheets/fs_trends-of-the-decade-for-finance_en_xg.pdf

19. Visible-Banking.com. (2010). Top 10 most-liked financial institutions on Facebook in October 2010 (617 pages, groups, apps in 67 countries). Retrieved October 27, 2010, from http://www.visible-banking.com/2010/10/top-10most-followed-financial-insitutions-on-twitter-in-october-2010-1333-accounts-in-68-countries.html. 